\title{
Preface to the CIESC 2009 Special Issue
}

\author{
Adenauer Correa Yamin ${ }^{1,2}$, Gerson Geraldo H. Cavalheiro ${ }^{1}$, Philippe Olivier A. Navaux ${ }^{3}$ \\ 1 Universidade Federal de Pelotas \\ Pelotas, Rio Grande do Sul, Brazil \\ 2 Universidade Católica de Pelotas \\ Pelotas, Rio Grande do Sul, Brazil \\ 3 Universidade Federal do Rio Grande do Sul \\ Pelotas, Rio Grande do Sul, Brazil \\ \{adenauer,gerson.cavalheiro\}@inf.ufpel.edu.br,navaux@inf.ufrgs.br
}

This special issue of the CLEI Electronic Journal consists of revised versions of the best papers presented at the XVII Iberian-American Conference on High Education in Computer Science, CIESC 2009, which took place in Pelotas, Brazil, in September 2009 concurrently with the 35th Latin American Conference on Informatics, CLEI 2009.

The Iberian-American Conference on High Education in Computer Science is a forum for discussing and exchanging ideas on topics related to CS education, covering topics from initiatives of high education to the promotion and formation for entrepreneurship. In 2009, 44 technical papers were submited to this Conference, from which the program committee has selected 18 to be presented: 12 as full papers and 6 as short papers. A second evaluation round have selected the 6 best papers to be published here.

We hope you will enjoy the reading! 